\title{
Os paradoxos entre os urbanos no município de Barcarena, Pará
}

\author{
The paradoxes between different urban spaces in the \\ municipality of Barcarena, Pará state, Brazil
}

Monique Bruna Silva Carmo, Sandra Maria Fonseca da Costa

Universidade do Vale do Paraíba (UNIVAP), São José dos Campos, SP, Brasil

\section{Resumo}

O processo de urbanização nas pequenas cidades da Amazônia, nas últimas décadas, tem transformado o cenário urbano e também o rural, os quais foram reestruturados e perderam suas características típicas. Apesar de existirem cidades fortemente dependentes dos recursos das florestas, há o surgimento de cidades que se desvincularam dessas atividades rurais, tornando-se conectadas ao mercado global por meio da indústria. 0 município de Barcarena, no Pará, é um exemplo desse processo e, apesar de sua economia estar voltada para a atividade industrial, possui uma população rural que se sobrepõe à população urbana. Nesse aspecto, o presente artigo objetiva compreender a reestruturação urbana desse município a partir da instalação de um complexo industrial e dos paradoxos urbanos que surgiram a partir desse processo. Para o seu desenvolvimento, foram utilizados dados coletados por meio de formulários aplicados aos domicílios urbanos, dados censitários e informações coletadas no município. A pesquisa demonstra incoerência de dados sobre urbanidade, questiona as proposições do Instituto Brasileiro de Geografia e Estatística (IBGE) e conclui que Barcarena ainda é uma "cidade da floresta", por conservar uma cultura e economia fortemente relacionada à floresta, e que Vila dos Cabanos é uma "cidade na floresta”, por apresentar funções logísticas fortemente ligadas ao exterior e desvinculadas da floresta.

Palavras-chave: Pequenas cidades. Amazônia. Cidade na e da floresta. Indústria.

\section{Abstract}

Over the past decades, the process of urbanization in the small towns of Amazonia has transformed the urban and rural sceneries, which were restructured and have lost their characteristics. Although there are cities deeply dependent on forest resources, there is the emergence of cities that have withdrawn this activity and become dependent on the productive sector connected with the global market, such as the industry. The municipality of Barcarena, Para state, is an example of this process. Even though its economy is based on industrial activity, its rural population overlaps its urban population. In this sense, this paper aims to study the urban restructuring of the municipality of Barcarena, from the installation of an industrial complex, and the urban paradoxes resulting from this process. This research was developed using data collected through questionnaires applied

MBSC é Geógrafa; Mestre em Planejamento Urbano e Regional (UNIVAP), e-mail: moniquebruna@ymail.com SMFC é Geógrafa; Doutora em Informação Espacial (USP), e-mail: sandra@univap.br 
in urban households, census data, and information collected in the Barcarena City Hall. This study shows the incoherence of data on urbanity; questions IBGE delimitations; and concludes that Barcarena is a "town of the forest" because it has kept its culture and economy closely related to it, and that 'Vila dos Cabanos' is a "town in the forest" because it presents strong logistic functions bound to the exterior and disconnected from the forest.

Keyword: Small cities. Amazon. City in and of the forest. Industry.

\section{Introdução}

Segundo Santos (2009), a urbanização brasileira representou, e ainda representa, por meio de um cenário global, as relações estabelecidas que estão cada vez mais ligadas ao modo de vida urbano, assim como o campo brasileiro, que também está mais próximo desse modo de vida. Esse urbano, segundo Santos (2009), vai se adequar às formas modernas, já encontradas em outros países há anos, que altera não somente a paisagem, mas também as relações sociais. Dessa forma, é inserido nesse espaço um novo aculturamento, por exemplo, o consumo, passando a ser o "novo" estilo de vida da sociedade contemporânea. Segundo Santos (2009, p. 117):

Legitimado pela ideologia do crescimento, a prática da modernização que assistindo no Brasil, desde o chamado "milagre econômico", fez o país se conduzir a enormes mudanças econômicas, sociais, políticas e culturais, apoiadas nos equipamentos modernos de parte do território, na produção de uma psicoesfera tendente a aceitar essas mudanças como um sinal de modernidade.

Como reflexo desse processo, a urbanização nas cidades brasileiras ocorreu de forma heterogênea, surgindo diferentes urbanos, como no caso da Amazônia. Na década de 1960, essa região, além de incorporar áreas distantes, também recebeu um conjunto de políticas governamentais que promoveu uma reorganização nas formas de produção do espaço urbano. Segundo Becker (2001), a intensificação do processo de urbanização na Amazônia resultou no aumento do número de cidades, porém o tamanho dessas delas diminuiu. As cidades passaram a ter um papel logístico, influenciando a intensificação da ocupação dessas áreas.

A partir de 1980, segundo Becker (1985), a Floresta Amazônica passou ser considerada urbanizada em função do número de moradores urbanos (maior do que 50\%); assim, os núcleos urbanos adquiriram uma grande importância para o cenário nacional. Naquele momento, as mudanças estruturais puderam ser observadas, principalmente, no que diz respeito à articulação do espaço, uma vez que foram criados espaços estratégicos com a intenção de alavancar a economia sob o ponto de vista da modernização.

0 município de Barcarena, localizado no Estado do Pará, foi um exemplo dessas transformações. Na década de 1980, as atenções das políticas públicas se voltaram para o município para que ele atendesse aos interesses do Estado e aos interesses externos, recebendo um grande projeto denominado de "Complexo Industrial da Alunorte".

A empresa influenciou a expansão do núcleo da Vila dos Cabanos, planejado para atender às demandas que iriam servir à empresa, tais como: residência para os trabalhadores, instalação de comércio, saúde, educação, entre outros. Essa indústria foi, e continua sendo, a grande responsável pela reestruturação do espaço urbano e rural de Barcarena. Apesar de o motor econômico do município ser a indústria, segundo os dados do censo do Instituto Brasileiro de Geografia e Estatísticas (IBGE, 2010), mais de $60 \%$ da população está localizada na área rural, enquanto que $40 \%$ encontram-se na área urbana. Esse dado chama a atenção considerando que o motor econômico do município é a indústria e que também houve reestruturações espaciais específicas para atender a uma demanda dessa indústria. Nesse aspecto, duas questões se apresentam: há algum paradoxo entre o urbano e rural em Barcarena que deva ser compreendido? Que urbano é esse?

Considerando essa discussão, este artigo procurou analisar como o município de Barcarena se reestruturou a partir da instalação da indústria Albrás (1984-2010), a qual produziu diferentes urbanos no município. Apresenta-se também uma análise da diferenciação entre o urbano e o rural, seguindo a caracterização 
proposta pelo IBGE (2010), desde o censo de 1991, o qual não incorporou as transformações urbanas do município às suas classificações.

Para realizar essa análise, optou-se por estudar dois lugares: a área-sede do município, Barcarena, e a Vila dos Cabanos, distrito rural que foi reestruturado para receber os trabalhadores da Albrás na década de 1980. Esse recorte da área de estudo, ou seja, a seleção do urbano-sede e do rural-urbano, possibilitou confrontar o conceito de urbano do IBGE e também levantar informações censitárias e de campo que permitiram realizar os confrontos entre as proposições conceituais de urbano e rural.

Para realizar a pesquisa, foram levantados dados censitários sobre população (urbana e rural), socioeconômicos e de infraestrutura básica, disponibilizados pelo IBGE (2010). Foram coletados, na Prefeitura Municipal de Barcarena como: dados de cadastro de estabelecimentos comerciais, o Plano Diretor Municipal e o Plano Urbanístico da Vila dos Cabanos.

Objetivou-se também conhecer o perfil dos moradores dessas duas áreas para que entendêssemos as relações desses moradores com a indústria e com os recursos da floresta, e, dessa forma, caracterizar o que diferenciava essas duas áreas em termos produtivos. Assim, para a realização desta pesquisa, foram aplicados formulários, considerando o nível de certeza de 95\%, em um universo de 500 domicílios, dos quais 218 eram na Vila dos Cabanos, e em um universo de 1.000 domicílios, dos quais 278 eram em Barcarena (sede). Seguindo as normas da ética em pesquisa, os formulários foram aplicados somente após a aprovação do Comitê de Ética em Pesquisa (CEP) da Universidade do Vale do Paraíba (UNIVAP), processo no 24297113.3.0000.5503. Cada formulário foi composto por seis perguntas referentes ao perfil dos moradores, de forma que fosse possível identificar a existência de uma relação ou vínculo entre esses dois lugares.

\section{Discussão conceitual}

\section{O urbano contemporâneo da Amazônia}

Na região Amazônica, mesmo que as formas tradicionais de vida do morador ribeirinho ainda estejam, de certa forma, ligadas ao campo, é possível observar a "modernização" dos espaços que estão se tornando cada vez mais diferentes e desiguais. Corrêa (1987) menciona que, a partir do momento em que as fronteiras se abriram, houve um surgimento de novos povoados, dando origem à criação de novas cidades. Enquanto umas se fortaleciam mais do que outras, como no caso de Belém, no Pará, e de Manaus, no Amazonas, outras eram esquecidas sob o ponto de vista político, econômico e social.

Em meados do século XX, a paisagem urbana da Amazônia se mostrou mais revigorada. Esse processo de urbanização, em grande parte, foi induzido pela intervenção estatal, após a década de 1960, quando o Estado passou a ser não apenas o controlador das terras, mas também o financiador de sua aquisição. Segundo Carmo (2015), entre 1950 e 1960, ocorreu um aumento de grupos empresariais que se fortaleceram diante dos conflitos por terras entre camponeses e fazendeiros, dando origem a um novo cenário local e regional.

O contexto histórico da ocupação da Amazônia registrou diferentes fases de organização e integração econômica. Segundo Gunn (1995, p. 121):

A articulação de novas relações empresarias, especialmente no final dos anos de 1990, foi frequentemente condicionada por mudanças nacionais de economia política, com repercussão nas políticas estatais que regularam o desempenho do setor petroquímico.

A ocupação do território possibilitou a instalação de grandes empreendimentos, sem que estes proporcionassem o retorno de investimentos necessários às cidades. Essa forma de organização espacial foi enfatizada seguindo um conjunto de estratégias de políticos e planejadores do Brasil, que buscaram o ideal desenvolvimentista. Como resultado, um novo sistema de capital e de investimento estrangeiro expandiu os empreendimentos nas cidades da Amazônia, elevando as taxas de crescimento delas.

Essas cidades amazônicas apresentaram, como esperado, formas distintas de crescimento, e, apesar de os urbanos serem muito semelhantes, não podem ser considerados como únicos. São vários urbanos que se confundem aos novos modos de vida que estão presentes nas cidades.

As possibilidades da racionalidade de planos urbanos, ou as preocupações com o saneamento, urbanismo e embelezamento, são excluídas pela 
expansão das formas privadas de apropriação do espaço, admitindo, neste caso, áreas de segregação, exclusão e invasão (Vicentini, 2004, p. 178).

Essas novas cidades abrigam uma forma contemporânea, que mantém vínculos ligados ao seu passado, como no município de Barcarena, que recebeu um complexo industrial e, como reflexo, vivenciou uma série de mudanças ligadas à modernização do espaço, porém não foram considerados a população e os costumes locais. Dessa forma, criou-se um urbano, mais moderno, e manteve-se outro urbano ribeirinho, tradicional, no mesmo território.

Cidade na floresta e da floresta: a visão do professor Trindade Junior

A discussão cidades na floresta e da floresta, abordada pelo professor Trindade Junior (Trindade, 2010), descreve o urbano contemporâneo da Amazônia, identificando as relações entre as cidades e o seu entorno, por exemplo, as relações que interferem na reestruturação do espaço urbano da região. Em meados do século XX, com a integração territorial - Norte, Nordeste e Centro-Sul -, é possível observar as alterações da cidade da floresta.

Este termo, "cidade da floresta", já utilizado por J. Browder e B. Godfrey, refere-se às típicas pequenas cidades ribeirinhas. Essas pequenas cidades, segundo Spósito \& Silva (2013), possuem uma materialidade no seu plano espacial; assim, constituem-se como forma no processo de urbanização e como imaterialidade que está ou estará relacionada aos seus fluxos, que serão traduzidas em seus sentidos econômicos, políticos, culturais etc. Ainda segundo a autora, a pequena cidade vai conter a mesma realidade dos outros centros urbanos no que diz respeito à sua totalidade, mas com características únicas e que resultam na forma desigual da divisão territorial do espaço.

As "cidades da floresta" transparecem um modo de vida rural, cujos recursos, em grande parte, são provenientes da floresta. Um exemplo dessas cidades são as cidades ribeirinhas que transitam entre a forma de vida local e a vida rural, tendo como base econômica a dependência da escala local e regional. Nesse sentido, essas cidades são, usualmente, pequenas, não modernizadas, que não acompanharam a "transformação" econômica e tecnológica das cidades industriais e que possuem uma realidade econômica e territorial muito desigual, em comparação às outras cidades brasileiras.

Em contraponto, existe outra cidade, a "cidade na floresta", que, segundo Trindade (2010), vai se expressar pela forma de articulação com as demais áreas externas a ela e vai estabelecer vínculos econômicos que não estarão ligados aos recursos da floresta. As formas de vida urbana nessas cidades ocorrerão como uma negação à antiga realidade e costumes. O espaço "floresta" se torna um meio de exploração sob o ponto de vista da atividade industrial, para a extração de madeiras, minério, fragrâncias, espécies animais e vegetais, turismo etc. Assim, essas "cidades na floresta" se tornam não apenas cidades estratégicas, mas também cidades logísticas (Trindade, 2010).

As cidades da Amazônia tiveram um papel de extrema importância na organização espacial da região: isso vai desde as cidades portuárias, que abrigavam os portos que exportavam produtos para o exterior, como é o caso de Belém e Manaus, até as cidades que tinham um papel de caráter comercial, as quais, segundo Castro (2008, p. 18), foram responsáveis pela estruturação urbana da Amazônia como um ambiente de fluxos econômicos.

Apesar de a infraestrutura ser quase inexistente nas pequenas cidades, o modo de vida, ainda assim, é considerado como urbano. Essas cidades, sejam elas "NA ou DA" floresta, sofreram diferentes transformações econômicas e políticas ao longo dos anos. As "cidades na floresta" tiveram uma reconfiguração do território de acordo com os interesses do Estado, os quais se voltaram para os grandes projetos que atuaram, e ainda atuam, como meios técnicos, tornando-se diferenciados por serem portadores de informações que se articulam dentro e fora do território.

Para a construção desses grandes projetos, foi necessária a criação de Company Towns, espaços construídos ou planejados especificamente para atender às necessidades dos complexos industriais. 0 município de Barcarena, nesse cenário, vai propiciar a configuração de dois urbanos: uma "cidade na floresta" e também como uma "cidade da floresta", pois, além de ter uma dependência da economia industrial, mantém, no mesmo território, uma realidade típica das pequenas cidades ribeirinhas da Amazônia. 


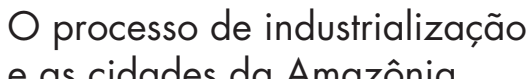

e as cidades da Amazônia

Santos (1995) destaca que o espaço vai adquirir sua importância a partir do momento em que ele é transformado e recebe as intervenções das "grandes coisas artificiais". As chamadas "coisas artificiais", ou seja, os grandes projetos, estão localizadas no espaço de forma que se crie uma nova organização territorial, sendo resultado de uma produção histórica realizada pelo homem, na qual se passa a negar a natureza do espaço "natural". Esse espaço, segundo Santos (1995), é formado por um conjunto de sistemas e objetos que se formou ao longo da história.

De um lado, os sistemas de objetos influenciam as formas como se dão as ações, e, de outro lado, o sistema de ações leva à criação de objetos novos ou se realiza sobre objetos pré-existentes. É desta forma que o espaço encontra sua dinâmica e passa a se transformar (Santos, 1995, p. 14).

Conforme surgem os objetos técnicos, por exemplo, hidrelétricas, estradas, cidades e fábricas, o espaço vai recebendo acréscimos, o que o torna cada vez mais técnico. É extremamente importante compreender o que é esse espaço, pois é por meio dele que podemos analisar as mudanças que ocorreram na origem dos sistemas que temos atualmente. Segundo Corrêa (2012), o espaço, mais do que a manifestação da complexidade social, é uma dimensão fundadora do ser no mundo.

A forma como ocorre à interação das práticas sociais no espaço é o que vai transformá-lo; dessa forma, passa a ocorrer a alteração da ordem espacial. Os sistemas que se estabelecem de forma universal no espaço, ou seja, os sistemas técnicos, sejam eles os mais dominantes, tendem a ser homogêneos em todos os lugares. Esses sistemas "mais dominantes" são aqueles que integram cultura, política e economia (Santos, 1995).

Até décadas passadas, isso não era possível, pois os sistemas se instalavam no território de formas distintas. É por isso que, atualmente, podemos compreender como os países periféricos se inseriram no contexto nacional e global, uma vez que ocorreu a multiplicidade de instalações de comandos dos sistemas técnicos que funcionam como sistemas de ações. Há uma intencionalidade por parte dos grandes agentes, que oferecem ideais simbólicos para assegurar os seus interesses. Segundo Santos (1995), essa intencionalidade mercantil é também simbólica.
Quando nos dizem que as hidrelétricas vêm trazer para o país e para uma região, a esperança de salvação da economia, da integração do mundo, a segurança do progresso, tudo isso são símbolos que nos permitem aceitar a racionalidade do objeto que vem, exatamente, destroçar nossa relação com a natureza e impor relações desiguais (Santos, 1995, p. 16).

As relações estabelecidas pelos sistemas técnicos têm uma grande capacidade limitada de invasão; os objetos que estão a serviço dos atores investem apenas no local, no qual apresentam a certeza de que irão obter retorno.

Naquelas regiões onde o sistema de objetos e o sistema de ações são mais densos, aí está o centro de poder. Naquelas outras áreas onde o sistema de objetos e o sistema de ações são menos complexos e menos inteligentes, aí está a sede da dependência (Santos, 1995, p. 17).

As inovações tecnológicas foram as grandes responsáveis pela integração econômica da Amazônia, considerando a existência de quatro períodos. 0 primeiro é o ciclo da borracha, que passou pela fase de ascensão e queda devido às inovações (Buarque, 1995, p. 30). 0 segundo ciclo se refere à agropecuária e minero-metalúrgica, na década de 1960, e foi marcado pelo intenso processo de industrialização no Brasil e pela inserção de uma nova divisão internacional do trabalho. Foram descobertas grandes reservas de recursos minerais na Amazônia, favorecendo o avanço tecnológico na região e também a abertura de rodovias, construção de hidrelétricas, transmissão a distância etc. (Buarque, 1995). Naquele momento, ocorreu a aliança de grandes empreendimentos externos (capital internacional) de minero-metalúrgica com o Estado nacional.

0 local que foi destinado à economia, baseada no trabalho familiar, foi alterado pelos efeitos provocados pela industrialização, modificando os costumes locais e refletindo na distinção da reprodução social. Esses grandes empreendimentos, quando se instalam em um determinado local, concentram impactos econômicos e sociais.

Tal dinâmica interferiu diretamente na organização do mercado de trabalho diversificando-o segundo setor e ramos de atividades, ocupações, qualificações, salários, políticas empresariais e gestão da mão-de-obra (Castro, 1995, p. 95). 
Essas novas formas de trabalho interferiram não somente na diversificação da mão de obra, mas também na predominância do regime assalariado, mais presente nos espaços urbanos.

Na década de 1970, iniciou-se uma nova fase na Amazônia, com a instalação de grandes obras, tais como a construção de estradas, ferrovias, aeroportos, usinas hidroelétricas, estruturação e reestruturação de centros urbanos, aeroportos, parques industriais (Castro, 1995). Essas obras se expandiram pelo território, fazendo-se necessária a contratação de mão de obra para esses serviços, o que fez com que grande parte da população migrasse para essas áreas em busca de serviços. Por exemplo, Serra Pelada, na década de 1982, alcançara o número de 70 mil trabalhadores, dos quais grande parte vinha de antigos serviços da construção civil (Castro, 1995).

Os programas governamentais, destinados às cidades da Amazônia, tinham como objetivo criar políticas de incentivo à ocupação com grandes projetos, buscando a diversificação setorial, subprogramas e projetos. Essa industrialização resultou em um discurso de modernização como possibilidade de desenvolvimento regional para as cidades da Amazônia.

Sob o ponto de vista regional, os grandes projetos industriais do Brasil procuraram recuperar o parque industrial, após 1980, com setor petroquímico, que ganhou destaque no cenário nacional. Com a reestruturação mundial dos mercados, novas tecnologias e investimentos (Gunn, 1995), foram identificadas as alterações nos processos de trabalho e também na concorrência entre as empresas.

A articulação de novas relações empresariais, especialmente no final dos anos de 1990, foi freqüentemente condicionada por mudanças nacionais de economia política, com repercussão nas políticas estatais que regularam o desempenho do setor petroquímico (Gunn, 1995, p. 121).

0 período de mudança, baseada nas experiências dos polos, gerenciados pelo Estado brasileiro, tratava-se de um planejamento centralizado, que cedeu forças para uma situação intermediária, liderada por um pensamento neoliberal com pactos de privatização, com modelos de integração concorrencial (Gunn, 1995).

Até fins de 1988, trata-se de um "momento" ainda dominado pelo peso de um regime de planejamento estatal dirigista que é, concomitantemente, a conclusão de um momento de gestão das forças empresariais regionalizadas (Gunn, 1995, p. 123).

Foi nesse cenário que a Indústria Albrás se instalou no município de Barcarena, modificando sua realidade e sua urbanidade, objeto de discussão deste artigo.

Definição da área de estudo: o município de Barcarena

O município de Barcarena está localizado no Estado do Pará (Figura 1). De acordo com o Plano Diretor de Desenvolvimento Urbano, Prefeitura Municipal (Barcarena, 2006) a chegada dos jesuítas foi possível somente mediante a doação de terras por parte de Francisco Rodrigues Pimenta, nas quais foi fundada a fazenda de Geribirié. Em 1758, foi elevada à categoria de freguesia; em 1898, à de Vila, mediante a Lei Estadual no 4, de 10 de maio de 1897; por fim, em 1943, tornou-se município, tendo sido desmembrada de Belém.

No que se refere à população, segundo os dados da Secretaria de Planejamento e Finanças do Estado do Pará (SEPOF), a população, em 1980, era estimada em 20.021 habitantes; em 1991, em 45.946 habitantes; no ano de 2000, em 63.268 habitantes; e, segundo o censo do IBGE (2010), em 99.859 habitantes. Entre 1980 e 2010, em 40 anos, houve um crescimento de $400 \%$.

O município está localizado na região do Delta do rio Amazonas e faz parte da Região Metropolitana de Belém; também faz limite com os municípios de Acará, Moju, Abaetetuba e Belém, e com a baía do Marajó e baía do Guajará. Sua área total é de $1.316,2 \mathrm{~km}^{2}$ e seu território é dividido por pequenas ilhas, tais como: Ilha das Onças, Ipiranga, Trambioca, Mucura, Arapari e outras.

\section{Paradoxos entre os urbanos de}

Barcarena: uma análise multitemporal

A dinâmica urbana e rural do município de Barcarena ocorreu de forma bem distinta ao longo dos últimos anos. Essa dinâmica, em sua maior parte influenciada pela industrialização, resultou na reestruturação do espaço, alterando a paisagem urbana e rural, além de modificar as relações socioespaciais do município. 


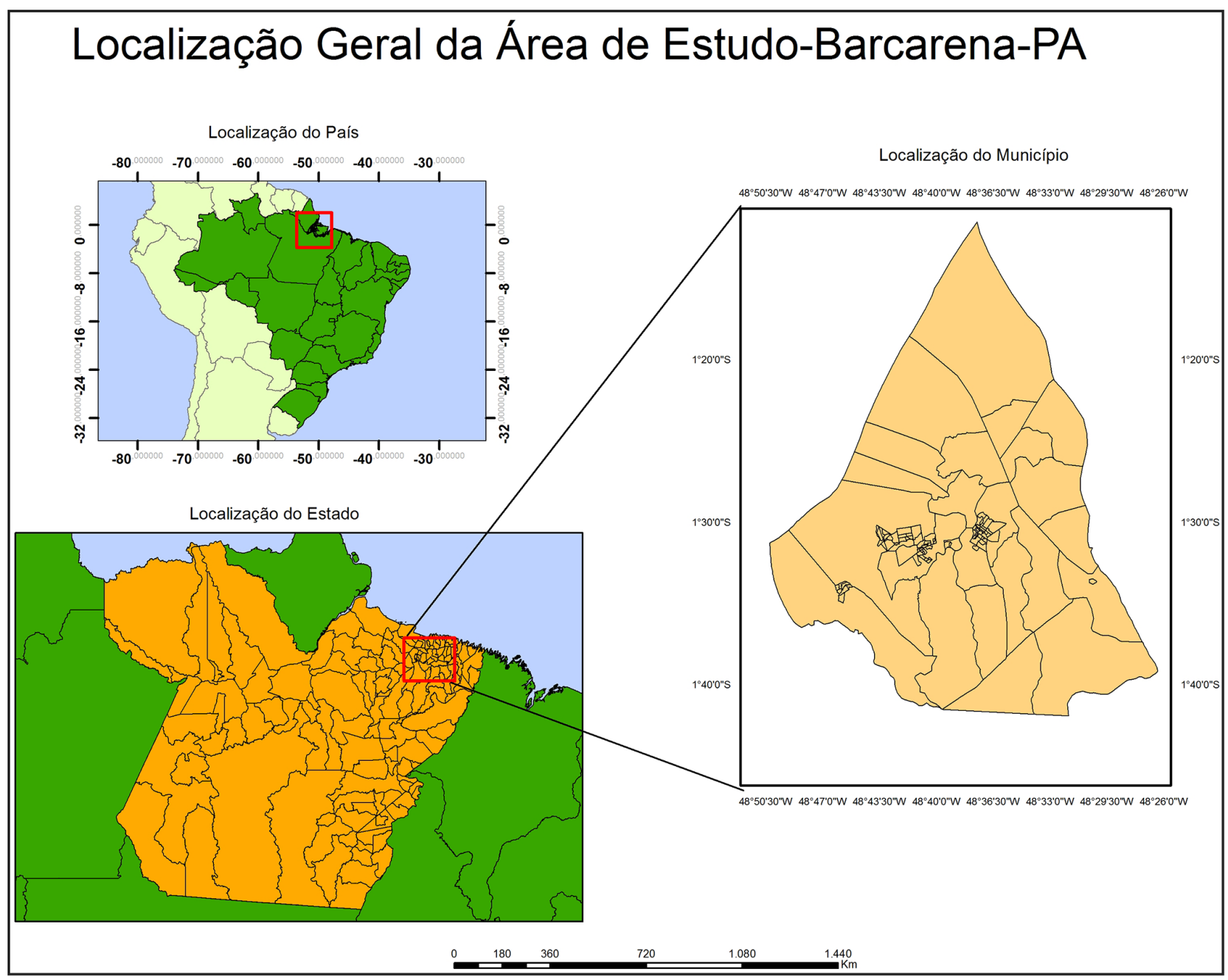

Figura 1 - Mapa de localização de Barcarena, no Pará Fonte: Elaborado pelos autores (2014).

Essa reestruturação foi importante para a formação socioeconômica local e regional.

No caso de Barcarena, assim como em outras cidades brasileiras, os grandes projetos foram responsáveis pela construção de áreas estratégicas que abrigavam, e ainda abrigam, uma infraestrutura que atendia às necessidades dos trabalhadores da empresa. Nesse sentido, a modernização foi a realização não somente de um desejo, mas também, de uma necessidade para atender aos interesses privados.

Esse complexo industrial, localizado na Vila dos Cabanos, está inserido em uma área que é considerada pelo IBGE (2010) como rural, localizada a $7 \mathrm{~km}$ da cidade de Barcarena (cidade-sede). Para a instalação da indústria, foi necessária a remoção de famílias que, predominantemente, eram compostas por pequenos produtores rurais que dependiam dos recursos provenientes da floresta.

A população, ali residente, foi considerada pelo Poder Público como invasora, com a necessidade de remoção, ou seja, as famílias foram removidas de seu espaço que, por direito, já era seu desde o início. Após a remoção dessas famílias, foi elaborado um plano urbanístico para a construção da Vila dos Cabanos, no qual estava incluída a construção de moradias para os trabalhadores da fábrica, iluminação pública, fornecimento de água e esgoto, arruamento, mercados etc. Enquanto essa área era planejada de forma estratégica, o restante do município, assim como a Barcarena-sede, apresentava um quadro crítico de serviços básicos, visível tanto na área urbana como rural. 
Entre 1980 e 2010, é possível observar que esse processo de reestruturação do espaço criou uma fragmentação espacial entre as comunidades do município de Barcarena. A Barcarena-sede, que antes era considerada a área mais importante do município, foi excluída dessa "modernização" espacial criada pelo complexo industrial. É possível identificar que havia no local duas realidades muito distintas, comparando-se a Vila dos Cabanos e a Barcarena-sede, assim como no restante do município.

Como mostra a Figura 2, essas "alterações" ou "reestruturações" tiveram início em 1984, com a construção do complexo industrial, de portos para o escoamento do alumínio, de casas e arruamentos. Houve também a ampliação do complexo industrial e a construção de outras indústrias na Vila do Conde (complexo industrial e também o terminal portuário, ambos pertencem à Alunorte), em Murucupi (Terminal Portuário Ponta da Montanha) e em Itupanema (Terminal Portuário Fronteira Norte - TERFRON).
A Figura 2, que apresenta um recorte espacial que engloba a cidade-sede, Barcarena, Vila dos Cabanos e a área de instalação da fábrica, foi estabelecida para demonstrar a dinâmica espacial verificada no município em função da instalação da indústria.

É possível observar que, ao longo dos anos, as mudanças espaciais no módulo analisado foram significativas. Em 1984, 73\% do uso e ocupação do solo era de florestas, 0,4\%, de vegetação secundária, 19\%, de água, 3,5\%, de superfície construída, e 4,8\%, de solo exposto. Em 1989, as florestas não se alteraram significativamente e ocupavam $72 \%$ da área, mesmo cenário para vegetação secundária (1\%) e corpos d'água (17\%). A superfície construída aumentou para $6 \%$ do total da área da subcena, passando a ocupar $6,8 \mathrm{~km}^{2}$, o que significou um aumento de 85\% em área em relação a 1984.

Em 2001, é possível observar um crescimento desordenado, com o surgimento de novas áreas, muitas delas consideradas como ocupações irregulares. Naquele ano, $64 \%$ da área estavam ocupados por florestas,

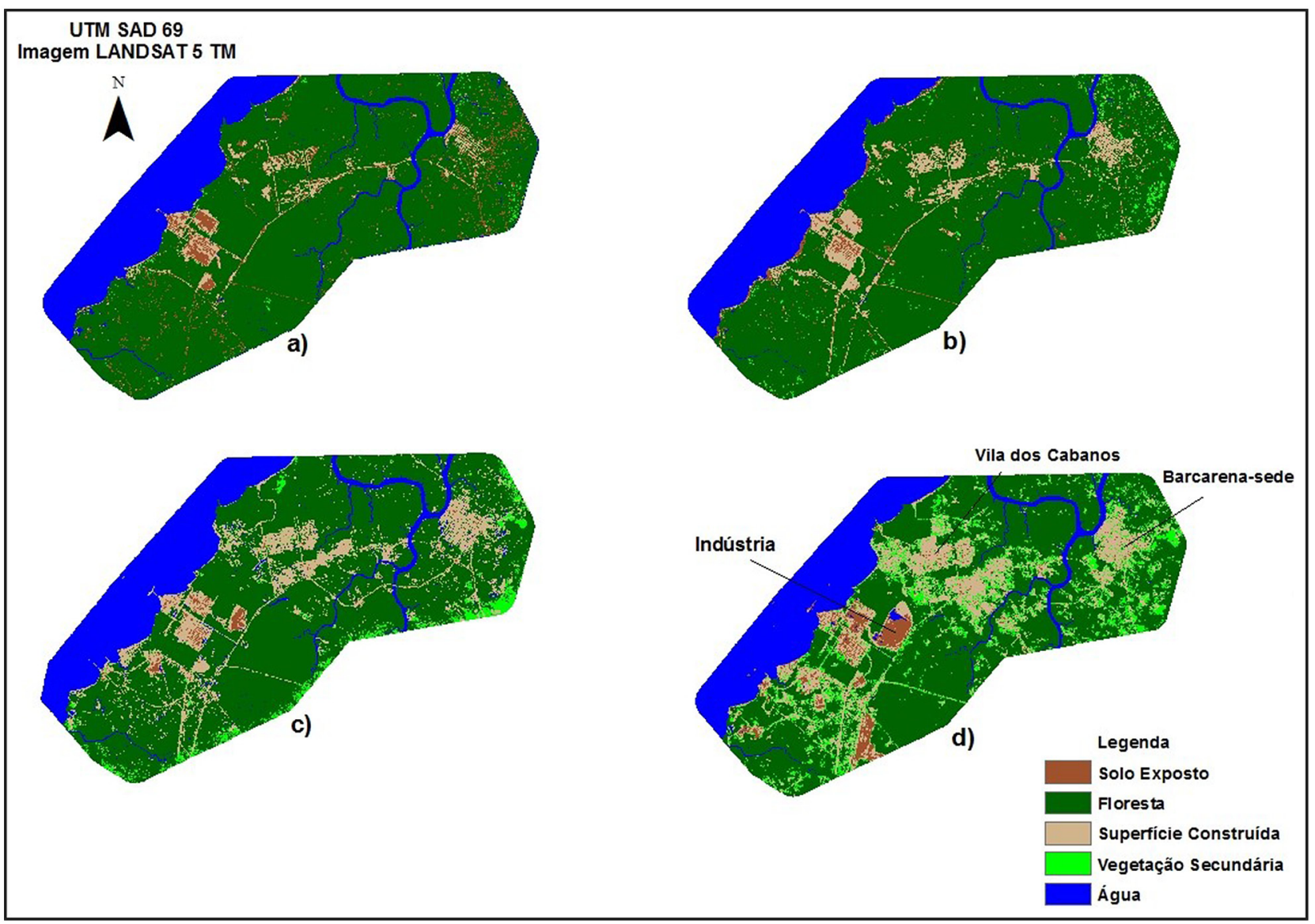

Figura 2 - Mapa de uso e ocupação do solo: (a) 1984; (b) 1989; (c) 2001; e (d) 2010 Fonte: Elaborado pelos autores (2014). 
havendo uma diminuição de 11\% em relação a 1989. A área construída apresentou um crescimento $14,4 \mathrm{~km}^{2}$, um aumento de $97 \%$ em relação a 1989. No ano de 2010, é possível identificar uma mudança mais intensa, com uma perda de $27 \%$ das florestas, com a vegetação secundária ocupando 9,4\%, a classe água, 19\%, a superfície construída, 15,3\%, e o solo exposto, 3,3\%. Entre os anos de 1984 e 2010, o crescimento da área construída foi de $334 \%$, demonstrando a dinamicidade das mudanças de uso e ocupação do solo, a qual se reflete na reestruturação do espaço urbano e rural de Barcarena.

Que urbano é esse? $O$ perfil urbano de Barcarena-Sede e da Vila dos Cabanos

Em meio a esta discussão, surge um paradoxo: a metodologia utilizada pelo IBGE para setorizar o espaço desse município. 0 censo (IBGE, 2010) vem setorizando a Vila dos Cabanos como rural desde 1991, enquanto que Barcarena-sede se manteve como urbana. A sede do município, de acordo com o IBGE, possui o perímetro urbano dividido por setores censitários.

Na Figura 3, é possível observar a divisão do município em setores censitários, nos anos de 1991, 2000 e 2010. Percebe-se que, durante 20 anos, foram mantidas as mesmas classificações de urbano e de rural do município, com pequenas alterações de limites, mas não de categoria. Percebe-se que o que foi alterado está localizado dentro do rural, onde se encontra a Vila dos Cabanos, aumentando a divisão dos setores rurais. Por que manter a mesma divisão se ambos são urbanos? Será que são urbanos? Esses espaços apresentam dinâmicas distintas, que podem ser observadas nos serviços e modos de vida da população. Pode-se assumir que há um paradoxo entre a definição dada pelo IBGE (2010) para o espaço urbano e para o rural - rural este que, na verdade, não existe e que se trata de um urbano estendido.

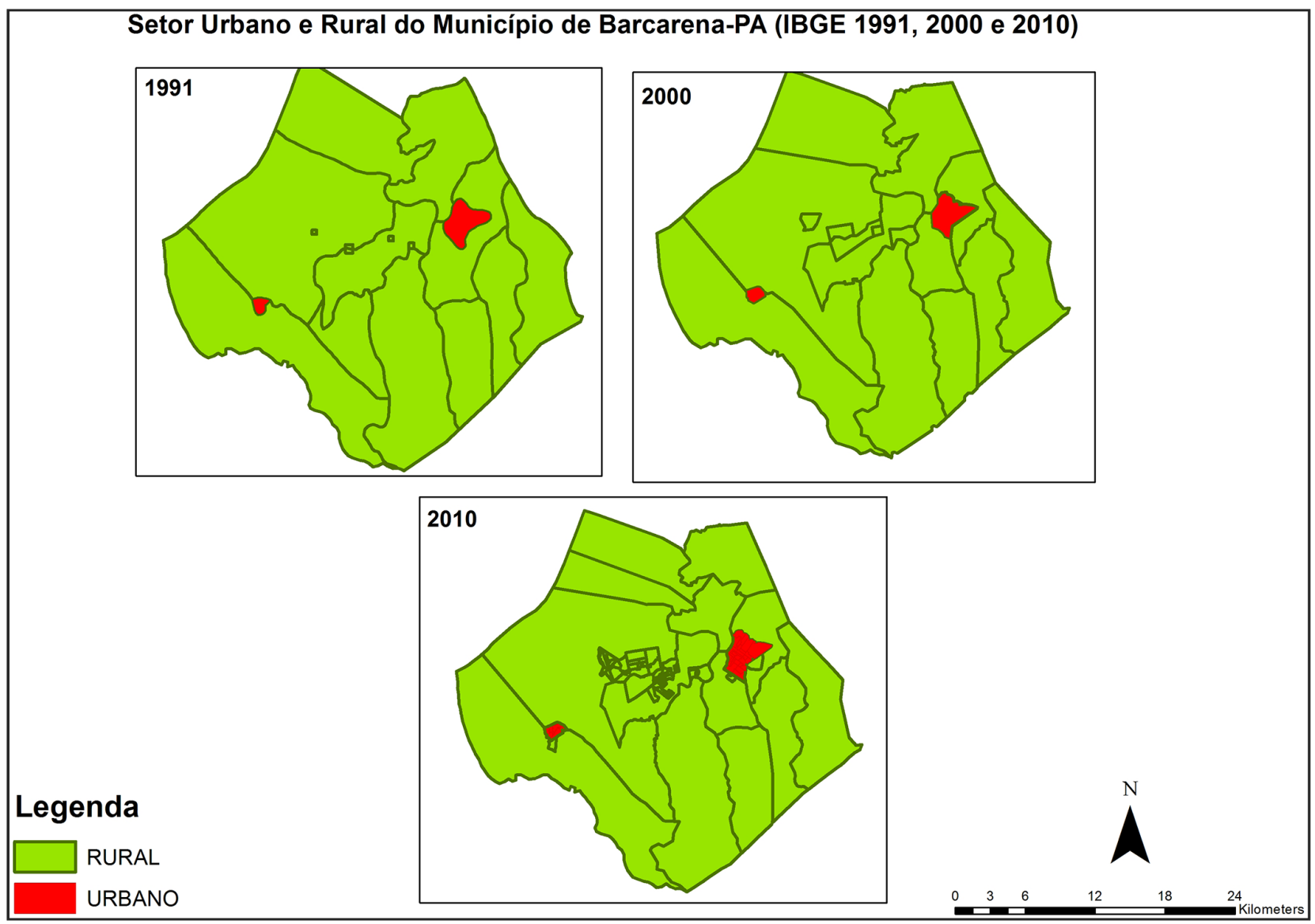

Figura 3 - Setores censitários do município de Barcarena, no Pará, em 1991, 2000 e 2010 Fonte: Elaborado pelos autores (2015). 
O núcleo de Barcarena, também chamado pelos moradores de velha Barcarena, abriga um comércio, preponderantemente, informal e o porto da cidade. A sede abriga muitas problemáticas usuais às pequenas cidades da Amazônia. Os próprios moradores se referem ao atual local de moradia como sendo um local esquecido, com muita precariedade de serviços básicos e ausência do Poder Público. Em contraposição, a Vila dos Cabanos possui um comércio mais robusto, com hipermercados, agências bancárias, além de muitos estabelecimentos comerciais.

No que se refere à infraestrutura, podemos identificar, no Gráfico 1, que há uma diferenciação interna no município entre esses dois urbanos, a sede e a Vila. Observa-se, claramente, que há os dois urbanos discutidos por Trindade (2010), a cidade na floresta e a cidade da floresta, ou seja, há duas cidades dentro do município de Barcarena.

$\mathrm{O}$ acesso à infraestrutura é diferente para os moradores da Vila dos Cabanos e para os residentes na velha Barcarena. Na sede (velha Barcarena), em 2010 (IBGE, 2010), apenas 0,35\% dos domicílios urbanos possuía acesso à rede geral de água, 1,7\% tinha acesso à rede geral de esgoto sanitário e 1,9\% não possuía banheiros. Em contraponto, na Vila dos Cabanos, 20\% dos domicílios possuíam acesso à rede geral de água, $15 \%$ dos domicílios possuíam acesso ao esgoto sanitário e $100 \%$ dos domicílios tinham banheiros. É possível afirmar que a Vila dos Cabanos, classificada como área rural pelo IBGE, e a
Barcarena-sede (urbana), apesar de estarem localizadas no mesmo município, são espaços contraditórios, principalmente pela forma como a Vila, categorizada como rural, foi setorizada pelo IBGE (2010).

Contraditória até mesmo quando os dados obtidos no censo do IBGE (2010) e os dados fornecidos pela PMB são comparados, pois a PMB classifica a Vila dos Cabanos como um núcleo urbano. Esse detalhe chamou atenção para esta discussão na pesquisa, uma vez que essas contradições de definição entre a Prefeitura Municipal de Barcarena no Plano Diretor de Desenvolvimento Urbano (Barcarena, 2006) e o IBGE (2010) podem trazer diferentes conflitos econômicos e sociais para o município, além de questionar quais foram os critérios usados pelo IBGE (2010) para chegar à conclusão de que esse espaço "dinâmico" e "estratégico" é realmente rural. Nas Figuras 4 e 5, há cenas das duas áreas, nas quais se observam as contradições apresentadas.

A Vila dos Cabanos foi, estrategicamente, criada para abrigar a infraestrutura e os serviços para os trabalhadores que forneceriam mão de obra para a empresa. 0 espaço foi repensado e reorganizado de forma que revelasse os costumes provenientes da modernização europeia e americana. A área-sede do município de Barcarena, que até então agregou o modo de vida e os costumes do ribeirinho, como menciona Trindade (2010), foi excluída da fase industrial, na qual o município foi inserido. A Barcarena (sede) não foi incluída em nenhum momento no plano urbanístico

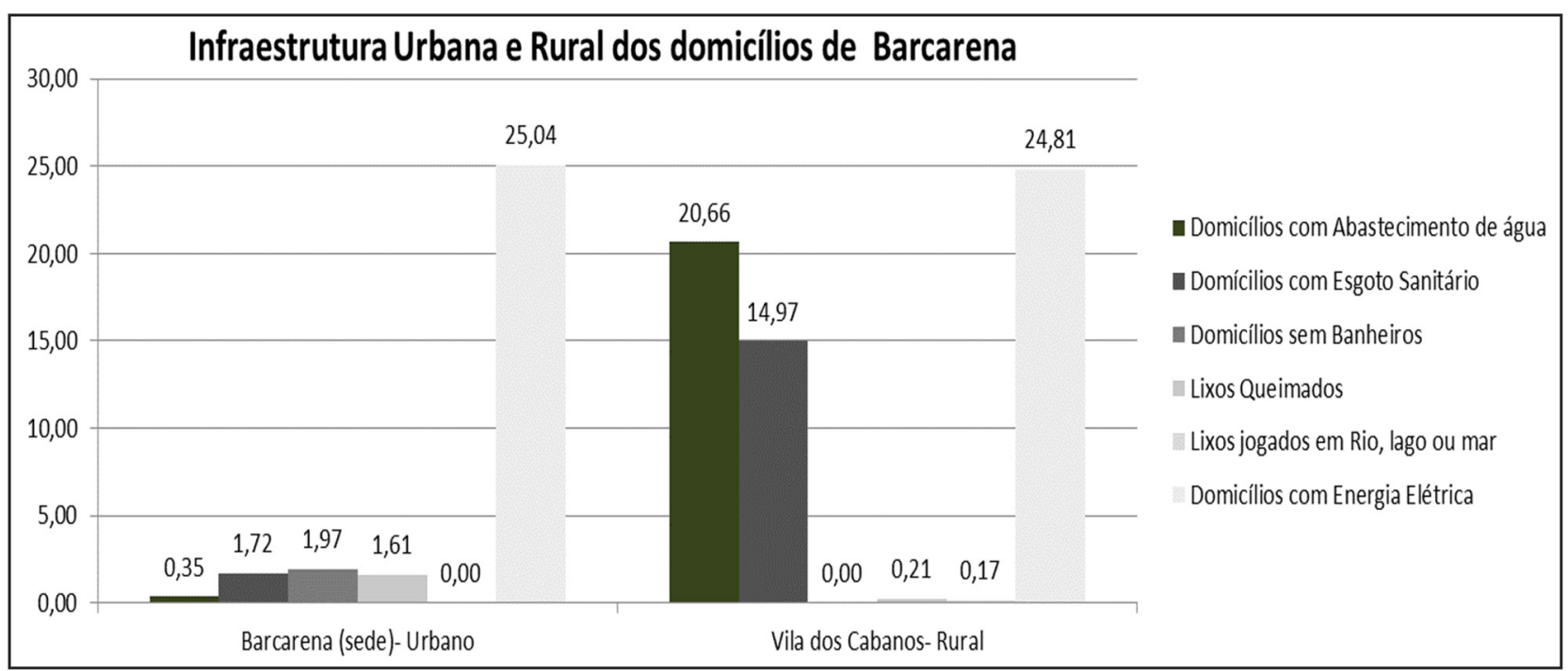

Gráfico 1 - Infraestrutura urbana e rural dos domićlios do município de Barcarena, no Pará Fonte: Elaborado pelos autores (2014). 

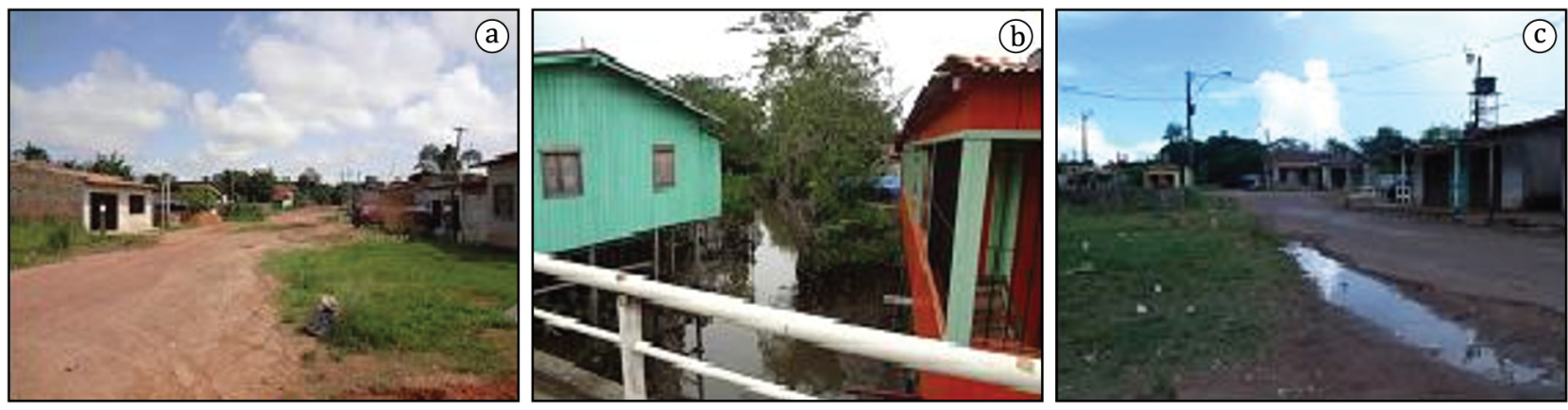

Figura 4 - Área urbana da cidade sede de Barcarena, no Pará: (a) rua sem pavimentação, próximo à área central; (b) casas de palafita; (c) esgoto a céu aberto Fonte: Elaborado pelos autores (2014).
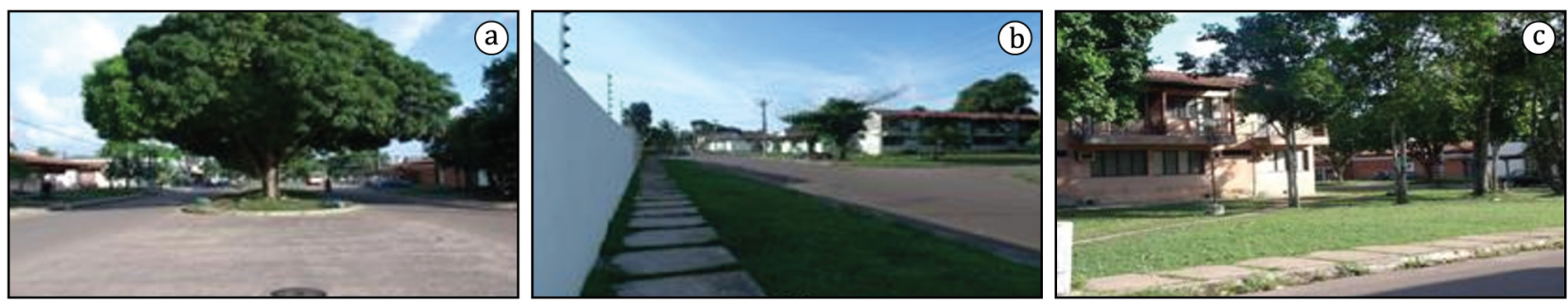

Figura 5 - Distrito de Vila dos Cabanos (área rurall): (a) ruas com pavimentação; (b) casas com cercas elétricas; (c) condomínios residenciais dos trabahahadores da Abrás/Alunorte Fonte: Elaborado pelos autores (2014).

elaborado para o município em 1989 e muito menos mostra algum tipo de relação econômica ou social que seria desenvolvida entre os espaços.

Além desses dados, há diferenças na quantidade de estabelecimentos de diferentes categorias econômicas, localizados nas duas "cidades". Barcarena (sede) possui menos estabelecimentos de comércio ( $12 \%$ a menos) e de serviços (171\%), e a formalidade é mais presente na Vila dos Cabanos (130\% a mais de estabelecimentos formais do que em Barcarena-sede), segundo dados obtidos no Plano Diretor de Desenvolvimento Urbano da Prefeitura Municipal de Barcarena (Barcarena, 2006).

Outro aspecto a ser destacado está relacionado ao perfil dos moradores que residem nesses locais e quais as suas relações com esses espaços, quais as atividades que desenvolvem, por exemplo, a profissão e a renda do entrevistado. Para levantar essas informações, como explicado na introdução deste artigo, foi aplicado um formulário a 508 famílias, em um trabalho de campo realizado no mês de janeiro de 2014. Objetivou-se identificar se o morador de Barcarena-sede possui algum vínculo com a Vila dos Cabanos ou se o morador da Vila está, de alguma forma, ligado à sede.

Uma das informações levantadas refere-se à profissão do responsável pelo domicílio (Tabela 1).
Em Barcarena (cidade-sede), representante da vida local ribeirinha, fica evidente a dependência dos benefícios sociais e a predominância de trabalhos informais, o que é muito comum nas pequenas cidades. 0 bairro Vila dos Cabanos, localizado dentro do mesmo município, possui características bem distintas do que se verifica em Barcarena (sede). Nesta, entre as famílias entrevistadas, predomina-se a atividade informal (28\%); os recursos provenientes da aposentadoria também são significativos para quase $12 \%$ das famílias; o emprego público se destaca para 9,5\% das famílias entrevistadas; a pesca se apresenta como uma atividade importante para $3,6 \%$ e o trabalho na indústria local é significativo para 3,3\%. Muitas mulheres desempenham funções "no lar" (aproximadamente 18\%). Na Vila dos Cabanos, predomina-se o emprego na indústria (quase 28\%), assim como a informalidade, na figura do autônomo, com aproximadamente $28 \%$.

Em relação à média salarial dos entrevistados (Tabela 2), as diferenças também chamam atenção. Em Barcarena (sede), mais de 50\% dos domicílios possuem uma renda média de até um salário mínimo. Na Vila dos Cabanos, mais de $42 \%$ dos entrevistados recebem mais de cinco salários mínimos. Barcarena 


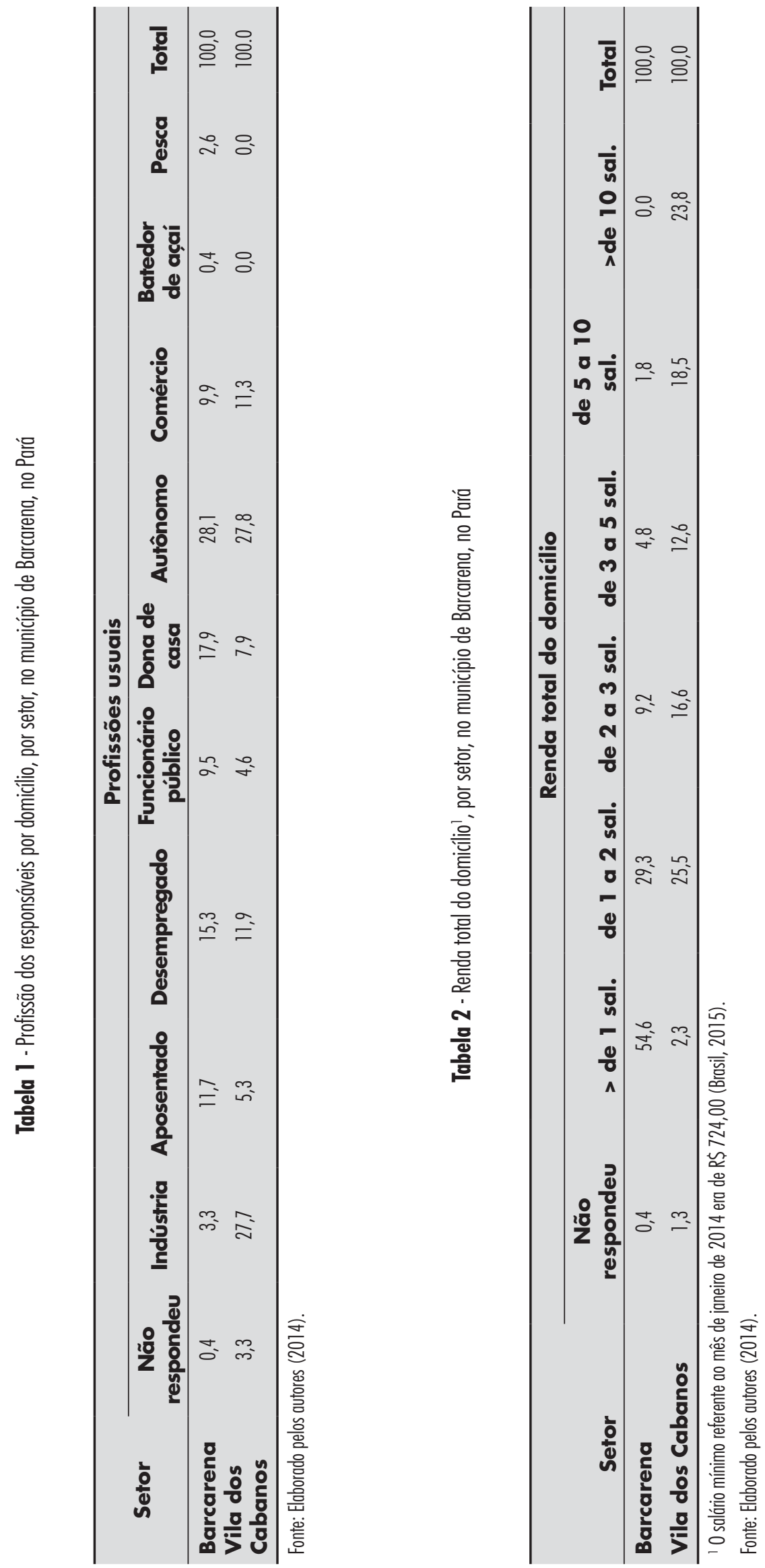


(sede) e Vila dos Cabanos são completamente distintas e parecem duas cidades dentro de um mesmo município. A renda da população nesses locais selecionados reforça mais ainda essas diferenças.

Quanto ao nível de escolaridade, ressalta-se o fato de, no bairro de Barcarena (sede), 42,21\% dos entrevistados possuírem ensino fundamental incompleto, $17,62 \%$, ensino fundamental completo, $13,52 \%$, ensino médio incompleto, $22,95 \%$, ensino médio completo, e 3,69\%, graduação ou pós-graduação. Nenhum dos entrevistados respondeu possuir formação técnica.

Na Vila dos Cabanos, 58,39\% dos chefes de domicílios possuem ensino médio completo, 18,12\%, graduação ou pós-graduação, 5,37\%, nível técnico, $14,77 \%$, ensino fundamental completo, $2,01 \%$, ensino fundamental incompleto, e 1,34\%, ensino médio incompleto. Essa diferença se justifica pelo fato dos trabalhadores da Vila estarem mais diretamente envolvidos com a indústria, o que necessita e exige pessoal qualificado.

Dessa maneira, é possível compreender que a diferenciação entre o espaço urbano e rural de Barcarena vai além de uma setorização. Esse espaço considerado "rural", na verdade, não existe. Trata-se de um espaço urbano, moderno e que atende a todas as exigências dos grandes projetos. Esse espaço tido como rural agrega o mais alto índice de infraestrutura e as melhores condições socioeconômicas em relação à área urbana (Barcarena-sede). Nesse sentido, fica difícil compreender quais critérios foram e ainda são utilizados pelo IBGE para determinar o espaço urbano e rural. Da mesma forma, o perfil dos moradores mostra que esses espaços são bem desiguais.

\section{Considerações finais}

Como é possível identificar nesta pesquisa, a instalação da indústria foi responsável pela transformação do espaço urbano e rural de Barcarena. A área classificada como rural abriga a maior parte da infraestrutura urbana do município. As modernizações das ruas e do comércio fazem dali um espaço diferenciado. Assim, esse rural se tornou uma extensão do urbano, ou melhor, um urbano de fato. Da mesma forma, apesar dessas transformações, há um urbano que se manteve fiel às suas origens ribeirinhas, com todas as deficiências de infraestrutura e serviços das pequenas cidades amazônicas.
A produção socioespacial de Barcarena favoreceu a formação de duas cidades dentro do mesmo município, a cidade na floresta e a da floresta. As atividades, que antes, em sua maior parte, eram exercidas na floresta, passaram a se direcionar para a atividade industrial. A cidade da floresta, que é caracterizada por Barcarena-sede, insere-se no cenário regional, reproduzindo as características típicas das pequenas cidades, relações com recursos da floresta, atividades como pesca, mercado informal, ou seja, as típicas relações socioculturais das pequenas cidades ribeirinhas.

Em contraposição, localizada a $7 \mathrm{~km}$ da sede, a Vila dos Cabanos se consolida como uma cidade na floresta, dependente das atividades provenientes do complexo industrial, que possui uma aderência ao mercado global, que se manifesta no município de forma estratégica e que atende aos interesses privados.

Esse paradoxo criado entre o urbano e rural nos possibilita entender que a setorização/classificação do espaço municipal, realizada pelo IBGE, em 1991, 2000 e 2010, não capta a realidade presente no município. Com isso, perguntamo-nos: quais outros pequenos, médios e grandes municípios vivenciam a mesma problemática? Quais são os verdadeiros parâmetros utilizados pelos órgãos públicos para definir o que é urbano e rural? E até que ponto essas setorizações beneficiam os grandes projetos e os grandes empresários?

Sabemos que a forma como as cidades brasileiras são setorizadas ainda é nebulosa. Os critérios adotados pelo IBGE para o urbano e o rural são os mesmos adotados desde 1991. Não podemos deixar de mencionar que a "setorização" do urbano e rural, usualmente, é estabelecida em conjunto entre o IBGE e prefeituras. Entretanto, fica difícil justificar informações tão contraditórias que são fornecidas por um órgão público, cujos dados alimentam as bases das pesquisas brasileiras.

Quando falamos da Vila dos Cabanos e Barcarena-sede, parece que estamos nos referindo a locais distantes espacialmente. Entretanto, são duas realidades distintas dentro do mesmo município, compostas por uma fragmentação, tanto social quanto espacial.

Lefebvre (2008) menciona que no fenômeno urbano há uma grandeza e uma complexidade que vão além dos instrumentos e conhecimentos da ação prática, e que esse tecido urbano prolifera-se de forma que corrói o modo de vida agrária e 
as mudanças do espaço urbano. 0 mesmo autor discute que o direito à cidade não é simplesmente um retorno às cidades tradicionais, nostálgica (Lefebvre, 2001, p. 138), mas sim o direito à vida urbana, "transformada, renovada", pois a realização da sociedade urbana "[...] exige uma planificação orientada às necessidades sociais, às necessidades da sociedade urbana". Assim, o direito à cidade, para os munícipes de Barcarena, perde-se nesse contexto, uma vez que a produção desse espaço não se dá de forma igual para o município como um todo. Para que ocorra esse direito à cidade, ou seja, para que todos os moradores tenham o mesmo acesso à sociedade urbana, à inclusão urbana, com infraestrutura e serviços urbanos de qualidade, é necessário que o direito à vida urbana ou rural seja planejado, transformado e renovado. É importante reformular o planejamento urbano e municipal, de forma a incorporar todos os aspectos que incluam a sociedade como um todo. Somente assim as desigualdades poderão ser amenizadas e será possível entender que o município existe e vai além da Vila dos Cabanos.

\section{Agradecimentos}

As autoras agradecem à Fundação de Amparo à Pesquisa do Estado de São Paulo (FAPESP), pelo apoio financeiro fornecido a esta pesquisa, por meio da concessão de bolsa de mestrado no país e da Bolsa de Estágio de Pesquisa no Exterior (BEPE). Agradecem também ao Anthropological Center for Training and Research on Global Environmental Change (ACT) da Indiana University e ao Instituto de Pesquisa e Desenvolvimento (IP\&D) da Universidade do Vale do Paraíba, pelo apoio técnico e de infraestrutura fornecido a esta pesquisa. À Prefeitura Municipal de Barcarena, pelas informações cruciais disponibilizadas para as análises aqui realizadas. E, principalmente, à população de Barcarena, pela atenção durante $\mathrm{a}$ coleta de dados.

\section{Referências}

Barcarena. Prefeitura Municipal. Secretaria de Planejamento Urbano. (2006, 31 de outubro). Lei Complementar no. 23, de 09 de outubro de 2006. Aprova o Plano Diretor de Desenvolvimento Urbano do Município de Barcarena. Barcarena: Diário Oficial do Município. ano VI no 10.
Becker, B. K. (1985). Fronteira e urbanização repensadas. Revista Brasileira de Geografia, 51(3-4), 357-371.

Becker, B. K. (2001). Revisão das políticas de ocupação da Amazônia: é possível identificar modelos para projetar cenários? Rio de Janeiro: Laboratório de Gestão do Território, Universidade Federal do Rio de Janeiro. Versão Preliminar.

Brasil. Ministério do Trabalho e Emprego - MTE. (2015). Brasília. Recuperado em 13 de agosto de 2015, de http:// portal.mte.gov.br/sal_min/

Buarque, S. C. F. (1995). Padrões tecnológicos e formas de ocupação da fronteira. In E. Castro, E. A. F. Moura, \&M. L. S. Maia (Eds.), Industrialização e grandes projetos: desorganização e reorganização do espaço (pp. 21-40). Belém: Editora Universitaria-UFPA.

Carmo, M. B. S. (2015). A singularidade do urbano de Barcarena, como cidade ribeirinha da região Amazônica (Dissertação de mestrado). Universidade do Vale do Paraíba, São José dos Campos.

Castro, E. (1995). Industrialização, transformações socias e mercado de trabalho. In E. Castro, E. A. F. Moura, \&M. L. S. Maia (Eds.), Industrialização e grandes projetos: desorganização e reorganização do espaço (pp. 21-40). Belém: Editora Universitaria-UFPA.

Castro, E. M. R. (2008). Cidades na floresta. São Paulo: Annablume.

Corrêa, R. L. (1987). A periodização da rede urbana da Amazônia. Revista Brasileira de Geografia, 4(3), 39-66. Recuperado em 13 de agosto de 2015, de http://biblioteca. ibge.gov.br/visualizacao/monografias/GEBIS\%20-\%20 RJ/RBG/RBG\%201987\%20v49_n3.pdf

Corrêa, R. L. (2012). Olhares geográficos: modos de ver e viver no espaço. Rio de Janeiro: Bertand Brasil.

Gunn, P. (1995). A política e a questão regional na indústria petroquímica brasileira 1987-1991: os grandes projetos: sistemas de ação e dinâmica espacial. In E. Castro, E. A. F. Moura, \&M. L. S. Maia (Eds.), Industrialização e grandes projetos: desorganização e reorganização do espaço (pp. 21-40). Belém: Editora Universitaria-UFPA.

Instituto Brasileiro de Geografia e Estatística - IBGE. (2010). Material institucional. Rio de Janeiro: IBGE. Recuperado em http://www.ibge.gov.br, de 10 de agosto de 2014. 
Lefebvre, H. (2001). O direito à cidade. São Paulo: Centauro.

Lefebvre, H. (2008). A revolução urbana. Belo Horizonte. Editora UFMG.

Santos, M. (1995). Os grandes projetos: sistemas de ação e dinâmica espacial. In E. Castro, E. A. F. Moura, \&M. L. S. Maia (Eds.), Industrialização e grandes projetos: desorganização e reorganização do espaço (pp. 21-40). Belém: Editora Universitaria-UFPA.

Santos, M. (2009). A urbanização brasileira. São Paulo: Hucitec.
Spósito, E. S., \&Silva, P. F. J. (2013). Cidades pequenas: perspectivas teóricas e transformações socioespaciais. Jundiaí: Paco Editoral.

Trindade, S. C. C., Jr. (2010). A cidade na Floresta: os "grandes Objetos" como expressões do meio técnicocientífico informacional no espaço Amazônico. Revista IEB, (50), 113-137.

Vicentini,Y.(2004). Cidade e história na Amazônia. Paraná: UFPA.

Recebido: Ago. 13, 2015

Aprovado: Out. 07, 2015 